\title{
GCU
}

Glasgow Caledonian

University

University for the Common Good

\section{Total hip arthroplasty improves pain and function but not physical activity}

Jeldi, Artaban Johnson; Deakin, Angela H.; Allen, David J.; Granat, Malcolm H.; Grant, Margaret; Stansfield, Ben W.

Published in:

Journal of Arthroplasty

DOI:

10.1016/j.arth.2017.02.002

Publication date:

2017

Document Version

Author accepted manuscript

Link to publication in ResearchOnline

Citation for published version (Harvard):

Jeldi, AJ, Deakin, AH, Allen, DJ, Granat, MH, Grant, M \& Stansfield, BW 2017, 'Total hip arthroplasty improves pain and function but not physical activity', Journal of Arthroplasty, vol. 32, no. 7, pp. 2191-2198.

https://doi.org/10.1016/j.arth.2017.02.002

\section{General rights}

Copyright and moral rights for the publications made accessible in the public portal are retained by the authors and/or other copyright owners and it is a condition of accessing publications that users recognise and abide by the legal requirements associated with these rights.

Take down policy

If you believe that this document breaches copyright please view our takedown policy at https://edshare.gcu.ac.uk/id/eprint/5179 for details of how to contact us. 
Title: Total hip arthroplasty improves pain and function but not physical activity

Artaban Johnson Jeldi ${ }^{\text {a,b }}$, PhD (artaban.jeldi@gjnh.scot.nhs.uk)

Angela.H. Deakin ${ }^{\text {b }}$ PhD (Angela.Deakin@gjnh.scot.nhs.uk)

David Allen ${ }^{\text {b }, ~ F R C S E d ~(T r a u m a ~ \& ~ O r t h o p a e d i c s) ~(D a v i d . A l l e n @ g i n h . s c o t . n h s . u k) ~}$

Malcolm. H. Granat ${ }^{c}$ PhD (m.h.granat@salford.ac.uk)

Margaret Grant ${ }^{\text {a }}$ PhD (M.grant@gcu.ac.uk)

Ben Stansfield ${ }^{\mathrm{a}}$ PhD (ben.stansfield@gcu.ac.uk)

\section{Authors: Address}

a) Institute for Applied Health Research, Glasgow Caledonian University, Glasgow, UK G4 OBA.

b) Department of Orthopaedics, Golden Jubilee National Hospital, Clydebank, Glasgow, UK. G81 4DY.

c) School of Health Sciences, University of Salford, Salford, UK. M6 6PU.

\section{Corresponding Author}

Dr Artaban Jeldi,

Orthopaedics Research, R\&D Department, Golden Jubilee National Hospital, Clydebank, Glasgow, UK

E-mail: artaban.jeldi@gjnh.scot.nhs.uk, ben.stansfield@gcu.ac.uk 


\section{Abstract}

Background:

People with hip osteoarthritis are likely to limited physical activity (PA) engagement due to pain and lack of function. Total hip arthroplasty (THA) reduces pain and improves function, potentially allowing increased PA. PA of THA patients was quantified to $12 \mathrm{~m}$ post-operation. The hypothesis was that post-operatively levels of PA would increase.

Methods:

PA of 30 THA patients ( $67 \pm 7$ years) was objectively measured pre-operatively and three and 12 months post-operation. Harris Hip Score (HHS), Oxford Hip Score (OHS) and six minute walk test (6MWT) were recorded. Mixed linear modelling was used to examine relationships of outcomes with time, BMI, age, gender and baseline HHS.

Results:

Time was not a significant factor in predicting sit-to-stand transitions, upright time, steps, cadence of walking bouts $>60$ s, or longest upright bouts. However, HHS, OHS and 6MWT all improved with time. Notably BMI was a significant predictor of upright time, steps, largest number of steps in an upright bout, HHS and 6MWT. Baseline HHS helped predict longest upright bout, cadence of walking bouts $>60 \mathrm{~s}$ and $\mathrm{OHS}$. The significant effect of participant as a random intercept in the model for PA outcomes suggested habituation from pre- to post-surgery.

Conclusions:

PA did not change from pre- to $12 \mathrm{~m}$ post-surgery despite improvement in HHS, OHS and 6MWT. Baseline BMI was a more important predictor of upright activity and stepping than time. Pre- and post-operative PA promotion could be used to modify apparently habitual low levels of PA to enable full health benefits of THA to be gained. 
1 Title: Total hip arthroplasty improves pain and function but not physical activity

2

3 Abstract

4 Background:

5 People with hip osteoarthritis are likely to limited physical activity (PA) engagement due to 6 pain and lack of function. Total hip arthroplasty (THA) reduces pain and improves function,

7 potentially allowing increased PA. PA of THA patients was quantified to $12 \mathrm{~m}$ post-operation.

8 The hypothesis was that post-operatively levels of PA would increase.

9 Methods:

PA of 30 THA patients (67 \pm 7 years) was objectively measured pre-operatively and three and 12 months post-operation. Harris Hip Score (HHS), Oxford Hip Score (OHS) and six minute walk test (6MWT) were recorded. Mixed linear modelling was used to examine relationships of outcomes with time, BMI, age, gender and baseline HHS.

Results:

Time was not a significant factor in predicting sit-to-stand transitions, upright time, steps, cadence of walking bouts $>60$ s, or longest upright bouts. However, HHS, OHS and 6MWT all improved with time. Notably BMI was a significant predictor of upright time, steps, largest number of steps in an upright bout, HHS and 6MWT. Baseline HHS helped predict longest upright bout, cadence of walking bouts $>60$ s and OHS. The significant effect of participant as a random intercept in the model for PA outcomes suggested habituation from pre- to post-surgery.

Conclusions:

PA did not change from pre- to $12 \mathrm{~m}$ post-surgery despite improvement in HHS, OHS and

6MWT. Baseline BMI was a more important predictor of upright activity and stepping than 
time. Pre- and post-operative PA promotion could be used to modify apparently habitual

26 low levels of PA to enable full health benefits of THA to be gained.

27

Keywords

Physical activity, Total Hip Arthroplasty

30

\section{List of Abbreviations}

32

THA Total hip arthroplasty

33 PA Physical activity

34 HHS Harris Hip Score

35 OHS Oxford Hip Score

36 6MWT Six minute walk test

37 BMI Body mass index

38

39

40 
Total hip arthroplasty (THA) leads to reduction in pain[1-3] and improvement in functional capacity[4-6] and quality of life $[7,8]$. Additionally THA is associated with enhanced walking endurance (longer distances covered in the 6 minute walk test $[9,10]$ ) and improved balance (faster performance of the timed-up-and-go-test[10,11]). However, there is emerging evidence that there are only small changes in free-living physical activity (PA) following surgery[12-15]. With reduction in pain, enhancement of endurance and speed of walking following THA, it might be expected that individuals would be able to participant in health enhancing PA. However, it is possible that pre-operative habitual patterns of PA are not altered. If pre-operative patterns of PA are ingrained (at low levels), then pre-operative measurements could be extremely useful in targeting person-centred interventions to disrupt these patterns, potentially enhancing long-term health prospects. While PA may have become habituated, it is possible that changes following surgery may be dependent on a range of factors. A person's gender may have an impact on surgical outcomes, as might their weight and age at the point of surgery. Also their pre-operative clinical condition may be important in determining outcomes.

The aim of this study was to enhance understanding of PA following THA by using objective measurement to characterise PA from pre-operation through recovery to twelve months post-operation. The relationship between PA change with time following surgery and gender, age, BMI and baseline clinical score (Harris Hip Score) was investigated. Primary physical activity outcomes included the number of sit-to-stand transitions per day, the time upright per day and the number of steps per day. Also secondary outcomes were quantified 
endurance (six minute walk test) and clinical outcomes (Harris Hip Score, Oxford Hip Score). The hypothesis was that all outcomes would improve following THA.

\section{Patients and Methods}

This was an observational cohort study. Ethical approval was obtained from the West of Scotland Research Ethics Committee 1 (12/WS/0098). The study population was all patients being seen for a primary total hip arthroplasty operation at an NHS elective arthroplasty centre. To ensure the external validity of the study results the inclusion / exclusion criteria were kept as wide as possible. Inclusion criteria for the study were patients who were able to give informed consent, were between 50-85 years old and could return for follow-up. Patients were excluded if they were undergoing a revision hip arthroplasty, had had a total hip or knee arthroplasty in the last 12 months, had extreme locomotor limitations due to cardio-pulmonary, central or peripheral nervous system deficits or spinal conditions or were diagnosed with a terminal disease (malignancy). From July to August 2012 and January to May 2013 (break in recruitment due to illness of lead investigator) all THA patients under the care of one consultant orthopaedic surgeon $(n=64)$ were reviewed for eligibility for the study. All eligible patients $(n=57)$ were approached for inclusion in the study. Published data to carry out an appropriate a-priori power calculation were not available. Therefore a target sample of 30 participants was set to provide a power of 0.8 to detect a difference of 1SD in outcomes with a significant level of 0.05 . All the study participants gave informed consent and the complete assessment was carried out by the lead author, a registered Physiotherapist. 
Participants were operated on by a single consultant surgeon (DA) or a trainee surgeon under his direct supervision. Using a posterior approach, all participants received either a Contemporary ${ }^{\circledR}$ cemented cup or Trident ${ }^{\circledR}$ uncemented cup with an X3 polyethylene liner and an Exeter ${ }^{\circledast}$ femoral component (Stryker Orthopaedics, Michigan, USA). The perioperative care for all participants (from pre-assessment through to discharge) followed the institution's enhanced recovery programme[16]. The aim of this programme was to accelerate patients' rehabilitation and reduce in- hospital length of stay (to 3-4 days) by implementing a multimodal anaesthetic regime combined with pre-operative education and early mobilisation.

Data were collected at three time points: Pre-operatively within the two weeks before operation; three months after operation; twelve months after operation.

PA data were collected objectively for up to seven days using the activPAL3 ${ }^{\text {TM }}$ monitor (50x35x7mm, 30g) (PAL Technologies Ltd. Glasgow, UK; software version 7.1.18)[17,18]. Data from this instrument classified activities into sedentary (sitting/lying), standing and stride events. Thus a record of posture (upright or not) and stepping activity was generated. The monitor was attached to the anterior aspect of the thigh of the non-operated leg (24 hour/day wear) using a waterproof surgical dressing (Duoderm extra thin hydrocolloid dressing (Convatec) or Opsite flexifix (Smith \& Nephew)). When compared to video based observation the activPAL3 ${ }^{\mathrm{TM}}$ has only a $0.27 \%$ difference in upright time detection and 3.34\% difference for step count in adults [19] during standardised activities. Whilst the upright time detection remains good in activities of daily living $(-0.19 \%$ agreement) there is considerable undercounting of small stepping activity within these activities (-86\%). This undercounting of small/slow steps associated with some ADLs is emphasised by the 
monitor's progressively poorer performance below $0.5 \mathrm{~m} / \mathrm{s}$ [20]. The monitor therefore records purposeful stepping activity, but is poor at recording small/slow incidental stepping.

111 Compliance with monitor wear was assessed by self-report and post-hoc data examination by the research team. Only self-reported full 24 hours periods of wear were considered for

113 inclusion. These records were manually inspected for apparent abnormalities. Any days with apparent abnormalities were excluded.

Primary outcome measures:

117 The primary outcome for the study was PA. To quantify the level of PA the following three 118 outcome measures were averaged over all 24 hour periods recorded: Sit-to-stand transitions/day; time spent upright/day (hours/day); steps/day.

Secondary outcome measures:

121 The following characteristics of the longer bouts of activity for each recording period were calculated: Duration of longest continuous upright bout over the recording period; largest number of steps in an upright bout across the recording period (not necessarily the same bout as the longest continuous upright bout); mean cadence (steps/min) of all walking bouts of longer than 60 s.

Participants were also assessed at all time points using the Harris Hip Score[21] (completed

127 by the lead author by measurement and interview), the Oxford Hip Score[22,23] (selfcompletion) and a six minute walk test [24]. The six minute walk test was conducted in a $30 \mathrm{~m}$ long corridor, which had regular rest stations at $10 \mathrm{~m}$ intervals. The participants were 
advised to walk up and down the corridor at a self-selected speed to achieve the maximum distance within 6 minutes. The participants were informed that they could take a break when and for how long needed at any point during the 6 minutes.

The age, gender, height, weight, BMI and comorbidities (from medical notes) of participants were recorded. Major complications (Death, Pulmonary Embolism/Deep vein Thrombosis, dislocation, infection, and revision) were noted.

\section{Data analysis and statistics}

Outcomes were characterised as mean (SD). To examine the change pre- to post-operation mixed linear models were used to model the relationship between each PA or clinical outcome parameter and time. As three time points were recorded time could only be modelled as quadratic. Models were adjusted for gender, baseline BMI, age and baseline Harris Hip Score (apart from Harris Hip Score). The shape of each outcome curve over time was modelled with each outcome measurement at Level 1 and each patient at Level 2. Fixed and random effects were included at the patient level (Level 2) and measurement level (Level 1). The fixed part of each model describes the average growth curve for the sample; the random part splits variation between subjects at the higher level and variation between time in the study of the same person at the lower level. The models allowed a unique growth curve to be generated for each subject based on his or her deviation from the average curve. An unstructured covariance structure was used.

Models were created adding covariates sequentially and comparing models using the $2 * \log L$ ikelihood (-2LnL). Covariates were only retained if there was a significant improvement in -2LnL (reduction of 3.84). The maximum likelihood method was used to 
estimate the coefficients so that unbiased estimates of $-2 \mathrm{LnL}$ were calculated. Once the

153 model had been selected the restricted maximum likelihood method was used to give

154 unbiased estimates of the coefficients. From this model predictions were made. Residuals

155 for both level 2 and level 1 were estimated and investigated, as was the variance of the

156 model over time. Model parameters and $95 \% \mathrm{Cl}$ are presented along with predictions.

157 All statistical analysis was conducted in SPSS 23 (SPSS Inc, Chicago, IL) with the level of 158 statistical significance taken to be $p<0.05$. 
Thirty participants $(21 \mathrm{~F} / 9 \mathrm{M})$ were recruited to the study. The STROBE flow diagram giving recruitment pathway and reasons for non-participation is given in Figure 1. All surgeries were successfully carried out. For the duration of the study (one year follow-up) there were no major complications. Of the 30 participants, 3 did not have 12 month data (Figure 1). All 30 participants' data were included in the mixed linear modelling. For the participants mean age was 67 years (range $50-82 \mathrm{y}$ ), height $165 \mathrm{~cm}$ (range $150-182 \mathrm{~cm}$ ), weight $82.9 \mathrm{~kg}$ (range 57.8-132.6kg), BMI $31 \mathrm{~kg} / \mathrm{m}^{2}\left(\right.$ range $19-43 \mathrm{~kg} / \mathrm{m}^{2}$ ) and pre-operative Harris Hip Score 50 (range 27-66) and Oxford Hip Score 15 (range 4-30). Indication for surgery in all the participants was osteoarthritis. Along with this diagnosis 13 participants had hypertension, 7 had cardiac abnormalities, 4 had Diabetes Mellitus, 7 had asthma/COPD and 2 participants had previous THA on the contralateral side. A median of six days of PA data were recorded at each time point. Mean and standard deviation of outcomes are presented (Table 1) with significant predictors within the mixed linear models (Table 2) and graphical evidence of trends with these significant predictors (Figure 2).

When examined using mixed linear models gender was not a significant predictor of any outcomes. Age was only a significant predictor of HHS $(b=0.38, p=0.047)$ with a higher age being associated with a higher HHS (Figure $2 \mathrm{~g}$ ).

Time was not a significant predictor of the number of sit-to-stand transitions per day, upright time per day, steps per day, longest upright bout, the largest number of steps in an upright bout or cadence based on the outcomes of the mixed modelling (Table 1 mean data, Table 2 model outcomes). However, BMI was a significant predictor of upright time per day $(b=-0.153, p=-0.003)$ (Figure 2a), steps per day $(b=-263, p=0.001)$ (Figure $2 b)$ and largest 
number of steps in an upright bout $(b=-144, p=0.001)$ (Figure $2 d)$. In each of these cases higher BMI predicted a lower level of PA. Additionally Baseline HHS predicted variation in the longest upright bout $(b=0.0325, p=0.053)$ (Figure $2 c)$ and the cadence of walking in bouts longer than 60s $(b=0.696, p=0.004)$ (Figure 2e). For all PA outcomes except the longest upright bout random intercepts explained a significant proportion of the outcome, indicating that participants tended to maintain the same level of PA in relation to the other participants across the study period.

Time and Time ${ }^{2}$ were significant factors in the model for HHS, OHS and 6MWT outcomes (all $p<0.001)$. Also BMI helped to predict outcomes for HHS $(b=-0.41, p=0.070)$ (Figure 2f) and 6MWT ( $b=-6.09, p=0.03$ ) (Figure 2i) with higher BMI indicating lower scores. HHS baseline value helped to describe OHS ( $b=0.19, p=0.053$ ) (Figure $2 \mathrm{~h}$ ) change over the study period. There was significant variation across the study period between participants in HHS, OHS and 6MWT as indicated by significant $(-2 \mathrm{LnL})$ contributions to the model of random intercepts.

\section{Discussion}

This study demonstrated that at one year post-operation primary THA patients had made little change to their free-living PA from pre-operation levels, with time not being a predictor in the mixed linear model. However, BMI was a significant predictor in the model for upright time and stepping activity. The significance of the random parameter of participant within the model coupled with the lack of a significant effect of time, suggested that participants were tending to maintain the same relative volumes of PA across the study 
period. This appears to indicate that pre-operative PA may have become habitual (possibly related to $\mathrm{BMI}$ ) and despite improvements in function of the joint, as seen in the improvement of clinical outcome measures, PA levels did not significantly increase postoperation.

There were a number of limitations to this study. The small size of the study and the participants being under the care of one consultant within one hospital could limit the generalisability of the results. In terms of study power, based on the standard deviation of the difference in steps per day from pre- to 12 months post-operation recorded in this study (2492), the sample used (27 full records) would have been sufficient to detect a difference of 1350 steps/day with a power of 0.8 and a confidence of 0.05 . In support of the generalizability of the results, the participants' age was similar to that reported in arthroplasty registers $[25,26]$ and similarly osteoarthritis was the main reason for operation. However, BMI (mean $31 \mathrm{~kg} / \mathrm{m}^{2}$ ) was higher than reported elsewhere[25,27]. It is widely accepted that by 12 months post-operatively patients have gained the maximum benefit from their THA. However, it is possible that increased function is obtained at longer followup or that function at one year had already begun to deteriorate due to other comorbidities. The original activPAL ${ }^{\mathrm{TM}}$ monitor has proven validity in adults [18] and older adults $[17,28]$. However, the step counting facility of the activPAL3 ${ }^{\mathrm{TM}}$ has limitations at slow stepping speeds as it under-counts slow, short step-length steps $[20,29]$. Therefore, the monitor may not have reliably detected stepping which was not 'purposeful'. A further issue is that this was an observational study of a surgical intervention. Theoretically, it would have been possible to perform an RCT with a no surgery arm to examine natural progression 
within this population. A more subtle limitation is that this study did not measure the desire of participants to increase their level of PA post-surgery. Therefore, even with improved function participants may not have increased PA as they lacked motivation.

The results of this study confirm the previous reports of only small changes in PA following THA '[14,15,30,31]. However, there were differences in outcomes, e.g. the current study (Table 1) found lower sit-to-stand transitions per day both pre-operatively and at 3 months post-operatively and whilst the upright time/day was similar pre-operatively, there were varying levels of agreement post-operatively compared to other studies. There were differences in participant demographics, with the current study population being older and more overweight than those of previous reports, which might explain these differences.

The mixed model outcomes indicated that gender did not significantly predict results for any outcome parameters within this cohort and that age was only significant within the prediction model for HHS. These results are perhaps surprising in that age might have been considered important in predicting PA as the study participants covered 50-82 years of age. However, BMI or Baseline HHS appeared to be more important. BMI was a predictor of both PA and clinical score outcomes, highlighting the importance of pre-operative BMI in predicting outcomes following surgery.

The inclusion of the Time ${ }^{2}$ term within the mixed model improved predictions of several outcomes (Harris Hip Score, Oxford Hip Score and six minute walk test), suggesting that there was a non-linear relationship with time. This is highlighted in mean scores for these outcomes where large improvements occurred to the 3 month post-operative time point, but only small changes from 3 to 12 months post-operative (Figures $2 f-i)$. 
In the current study additional PA measures were added to those previously reported. The

251 longest upright bout and largest number of steps in an upright bout provide quantification of the longest times participants performed 'functional' tasks requiring the upright posture. Time was not a significant factor in predicting these outcomes (Table 2), indicating that participants were not extending their loaded use of their new hip joints. Similarly cadence of stepping for bouts longer than 60 s gives an insight into the intensity of stepping over extended periods. Whilst cadence increased across the study period (Table 1), this was not significantly predicted by time (Table 2 ) and still remained below that of age matched peers (93 ( \pm 12$)$ against $107 \mathrm{steps} / \mathrm{min}$ ) [32-34]. The longest upright bout model did not have a significant random effect of participant suggesting that there was not a consistent ranking of participants with time (Table 2). It is possible that this outcome is highly influenced by particular social events or functional activities, pointing to a need to gather contextual information to gain a full understanding of the reasons for these patterns. However, the largest number of steps in an upright bout did have significant random effects of participant, suggesting similar volumes of stepping within one bout across the study period by participants.

The lack of time as a significant predictor within the model coupled with the significant random effect of participant suggests that pre-operative PA (except longest upright bout) may be habituated. Therefore, if pre-operative PA was measured, interventions could be used to target those likely to have low PA post-operatively to attempt to modify long-term behaviour. Enhancing PA has demonstrated secondary benefits of improving health (e.g. lower risk of cancer, ischemic events, diabetes [35] and enhanced quality of life[36,37]). A 
etc., could be used to attempt to maximise the potential gains from THA in terms of overall health improvement. The significance of BMI within several PA outcome models reinforces the need to consider this as an important factor in health promotion alongside PA promotion.

277 As expected [9,30], both Harris Hip Score and Oxford Hip Score highlighted improvement 278 from pre- to post-operation, as did 6MWT (values similar to previous studies [12,31]). However, there was not an accompanying increase in PA levels, indicating that these measures cannot be used as surrogates for PA, i.e. that it is necessary to measure free-living PA directly to gain insight into any changes following surgery.

\section{Conclusions}

In this study primary total hip arthroplasty patients did not make significant changes in the volume of PA performed at one year post-operation and it appeared that participants tended to maintain the same relative level of PA in relation to their peers. However, standard clinical outcome measures improved, showing an increase in function. This may indicate that habitual free-living PA patterns are established pre-operatively, perhaps related to $\mathrm{BMI}$, and these are not altered by the better function and pain reduction given by a THA. These results may indicate that intervention to modify habitual low levels of PA, associated with declining long term health, could be necessary in a proportion of primary THA patients to allow them to fully exploit the additional function that their new joint gives them. 


\section{References:}

[1] Montin L, Leino-Kilpi H, Suominen T, Lepistö J. A systematic review of empirical studies between 1966 and 2005 of patient outcomes of total hip arthroplasty and related factors. J Clin Nurs 2008;17:40-5. doi:10.1111/j.1365-2702.2007.01944.x.

[2] Banerjee M, Bouillon B, Banerjee C, Bäthis H, Lefering R, Nardini M, et al. Sports activity after total hip resurfacing. Am J Sports Med 2010;38:1229-36. doi:10.1177/0363546509357609.

[3] Learmonth ID, Young C, Rorabeck C. The operation of the century: total hip replacement. Lancet 2007;370:1508-19. doi:10.1016/S0140-6736(07)60457-7.

[4] Vissers MM, Bussmann JBJ, de Groot IB, Verhaar J a N, Reijman M. Walking and chair rising performed in the daily life situation before and after total hip arthroplasty. Osteoarthritis Cartilage 2011;19:1102-7. doi:10.1016/j.joca.2011.06.004.

[5] Bhave A, Mont M, Tennis S, Nickey M, Starr R, Etienne G. Functional problems and treatment solutions after total hip and knee joint arthroplasty. J Bone Joint Surg Am 2005;87 Suppl 2:9-21. doi:10.2106/JBJS.E.00628.

[6] Dawson J, Fitzpatrick R, Murray D, Carr A. Comparison of measures to assess outcomes in Total Hip Replacement surgery. Qual Heal Care 1996;5:81-8.

[7] Sliwinski M, Sisto S. Gait, quality of life, and their association following total hip arthroplasty. J Geriatr Phys Ther 2006;29:10-7.

[8] Andreas L, Robert B. The Effect of of Elective Total Hip Replacement on HealthRelated Quality of Life. J Bone Jt Surg 1993;75:1619-25.

[9] Heiberg KE, Ekeland A, Bruun-Olsen V, Mengshoel AM. Recovery and prediction of physical functioning outcomes during the first year after total hip arthroplasty. Arch Phys Med Rehabil 2013;94:1352-9. doi:10.1016/j.apmr.2013.01.017.

[10] Kennedy DM, Stratford PW, Wessel J, Gollish JD, Penney D. Assessing stability and change of four performance measures: a longitudinal study evaluating outcome following total hip and knee arthroplasty. BMC Musculoskelet Disord 2005;6:3. doi:10.1186/1471-2474-6-3.

[11] Oosting E, Jans MP, Dronkers JJ, Naber RH, Dronkers-Landman CM, Appelman-de 
Vries SM, et al. Preoperative home-based physical therapy versus usual care to improve functional health of frail older adults scheduled for elective total hip arthroplasty: a pilot randomized controlled trial. Arch Phys Med Rehabil 2012;93:610-6. doi:10.1016/j.apmr.2011.11.006.

[12] de Groot I, Bussmann H, Stam H, Verhaar J. Small increase of actual physical activity 6 months after total hip or knee arthroplasty. Clin Orthop Relat Res 2008;466:2201-8. doi:10.1007/s11999-008-0315-3.

[13] Vissers MM, Bussmann JB, Groot IB de, Verhaar JAN, Reijman M. Physical functioning four years after total hip and knee arthroplasty. Gait Posture 2013;38:310-5. doi:10.1016/j.gaitpost.2012.12.007.

[14] Harding P, Holland AE, Delany C, Hinman RS. Do activity levels increase after total hip and knee arthroplasty? Clin Orthop Relat Res 2014;472:1502-11. doi:10.1007/s11999-013-3427-3.

[15] Arnold JB, Walters JL, Ferrar KE. Does Physical Activity Increase After Total Hip or Knee Arthroplasty for Osteoarthritis? A Systematic Review. J Orthop Sport Phys Ther 2016;46:431-42. doi:10.2519/jospt.2016.6449.

[16] McDonald D, Siegmeth R, Deakin A, Kinninmonth AWG, Scott NB. An enhanced recovery programme for primary total knee arthroplasty in the United Kingdom-follow up at one year. Knee 2012;19:525-9. doi:10.1016/j.knee.2011.07.012.

[17] Grant PM, Ryan CG, Tigbe WW, Granat MH. The validation of a novel activity monitor in the measurement of posture and motion during everyday activities. Br J Sports Med 2006;40:992-7. doi:10.1136/bjsm.2006.030262.

[18] Ryan CG, Grant PM, Tigbe WW, Granat MH. The validity and reliability of a novel activity monitor as a measure of walking. Br J Sports Med 2006;40:779-84. doi:10.1136/bjsm.2006.027276.

[19] Sellers C, Dall P, Grant M, Stansfield B. Validity and reliability of the activPAL3 for measuring posture and stepping in adults and young people. Gait Posture 2016;43:42-7. doi:http://dx.doi.org/10.1016/j.gaitpost.2015.10.020.

[20] Stansfield B, Hajarnis M, Sudarshan R. Characteristics of very slow stepping in healthy adults and validity of the activPAL3 ${ }^{\text {TM }}$ activity monitor in detecting these steps. Med 
Eng Phys 2014. doi:10.1016/j.medengphy.2014.10.003.

[21] Söderman P, Malchau H. Is the Harris hip score system useful to study the outcome of total hip replacement? Clin Orthop Relat Res 2001:189-97.

[22] Dawson J, Fitzpatrick R, Murray D, Carr A. Questionnaire on the perceptions of patients about total knee replacement. J Bone Jt Surg 1996;78:185-90.

[23] Wylde V, Learmonth I, Cavendish V. The Oxford hip score : the patient' s perspective. Ealth Qual Life Outcomes 2005;8:1-8. doi:10.1186/1477-7525-3-66.

[24] Rikli R, Jones J. The Reliability and Validity of a 6 Minute Walk as a measure of physical endurance in older adults. J Aging Phys Act 1998;6:363-75.

[25] O’Neill M, OO'Neill G, Perkins N. Scottish Arthroplasty Project Biennial Report 2014. 2014.

[26] Göran Garellick, Kärrholm J, Lindahl H, Malchau H, Rogmark C, Rolfson O. Swedish Hip Arthroplasty register : Annual report 2013. 2013. doi:10.1111/epp.12066.

[27] Tudor-Locke C, Craig CL, Thyfault JP, Spence JC. A step-defined sedentary lifestyle index : 5000 steps / day. Appl Physiol , Nutr Metab 2013;114:100-14.

[28] Grant PM, Dall PM, Kerr A. Daily and hourly frequency of the sit to stand movement in older adults: a comparison of day hospital, rehabilitation ward and community living groups. Aging Clin Exp Res 2013;23:437-44. doi:10.1007/BF03325239.

[29] Taraldsen K, Askin T, Sletvold O, Einarsen E, Bjastad K, Helbostad J. Evaluation of a Body-Worn Sensor System to Measure Physical Activity in Older People With Impaired Function. vol. 91. 2011.

[30] de Groot IB, Bussmann JB, Stam HJ, Verhaar J a N. Actual everyday physical activity in patients with end-stage hip or knee osteoarthritis compared with healthy controls. Osteoarthritis Cartilage 2008;16:436-42. doi:10.1016/j.joca.2007.08.010.

[31] Vissers MM, Bussmann JB, de Groot IB, Verhaar J a N, Reijman M. Physical functioning four years after total hip and knee arthroplasty. Gait Posture 2013;38:310-5. doi:10.1016/j.gaitpost.2012.12.007.

[32] Kim WS, Kim EY. Comparing self-selected speed walking of the elderly with selfselected slow, moderate, and fast speed walking of young adults. Ann Rehabil Med 
383

[33] Menz HB, Lord SR, Fitzpatrick RC. Age-related differences in walking stability. Age Ageing 2003;32:137-42.

[34] Tudor-Locke C, Barreira T V., Brouillette RM, Foil HC, Keller JN. Preliminary comparison of clinical and free-living measures of stepping cadence in older adults. J Phys Act Heal 2013;10:1175-80.

[35] Warburton DER, Nicol CW, Bredin SSD. Health benefits of physical activity: the evidence. Can Med Assoc J 2006;174:801-9. doi:10.1503/cmaj.051351.

[36] Fujita K, Makimoto K, Tanaka R, Mawatari M, Hotokebuchi T. Prospective study of physical activity and quality of life in Japanese women undergoing total hip arthroplasty. J Orthop Sci 2013;18:45-53. doi:10.1007/s00776-012-0318-5.

[37] Rolving N, Obling KH, Christensen FB, Fonager K. Physical activity level, leisure activities and related quality of life 1 year after lumbar decompression or total hip arthroplasty. Eur Spine J 2013;22:802-8. doi:10.1007/s00586-012-2535-1.

\section{Suppliers}

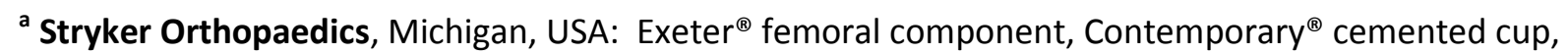
Trident ${ }^{\circledR}$ uncemented cup, $\mathrm{X} 3$ polyethylene liner.

${ }^{\text {b }}$ PAL Technologies Ltd. Glasgow, UK: activPAL3 ${ }^{\mathrm{TM}}$ 


\section{List of Figures}

Figure 1 Strobe flow chart of participant recruitment.

Figure 2 Model outcomes for significant relationships by months-post operative. Note in figures a) to e) for illustrative purposes time and time ${ }^{2}$ have been left in the models even though they were not significant (see Table 2 for significant model parameters). a) Upright time by BMI; b) Steps by BMI; c) Longest upright bout by Harris Hip Score baseline; d) Largest number of steps in an upright bout by BMI; e) Cadence of stepping bouts $>60$ s by HHS baseline; f) Harris Hip Score by BMI; g) Harris Hip Score by age; h) Oxford Hip Score by Harris Hip Score baseline; i) Six minute walk test by BMI. 


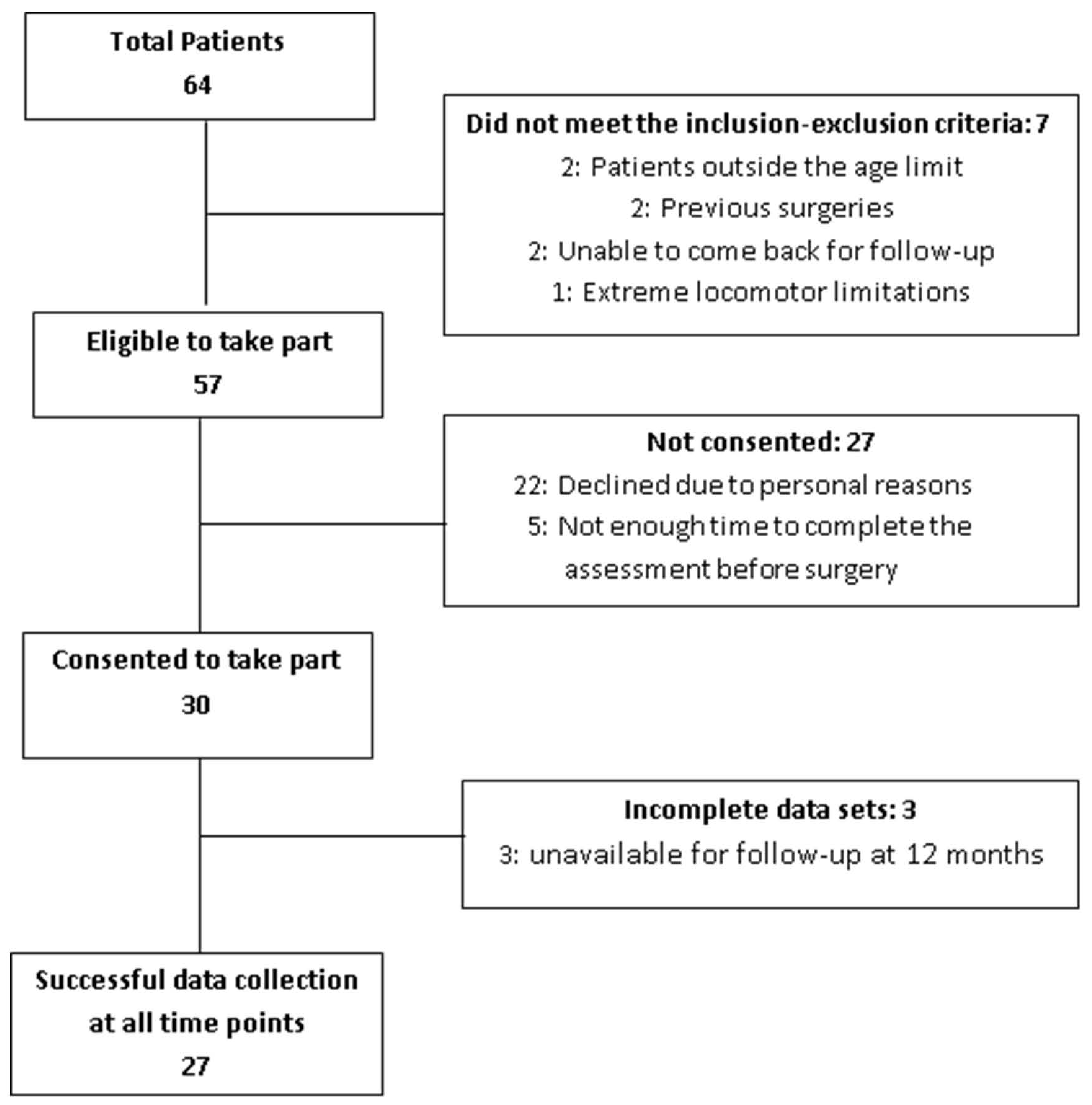


a)

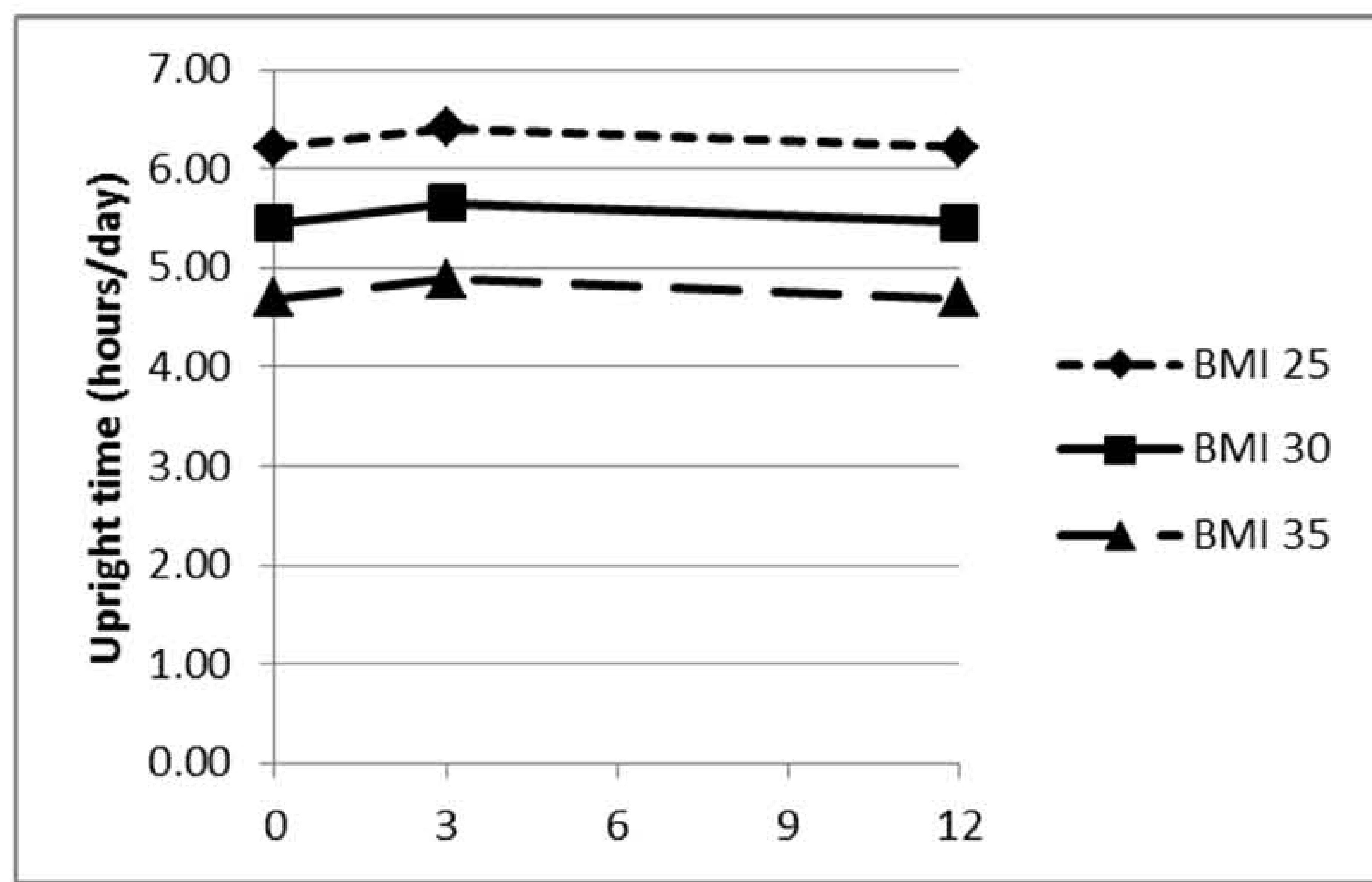

b)

c)

d)
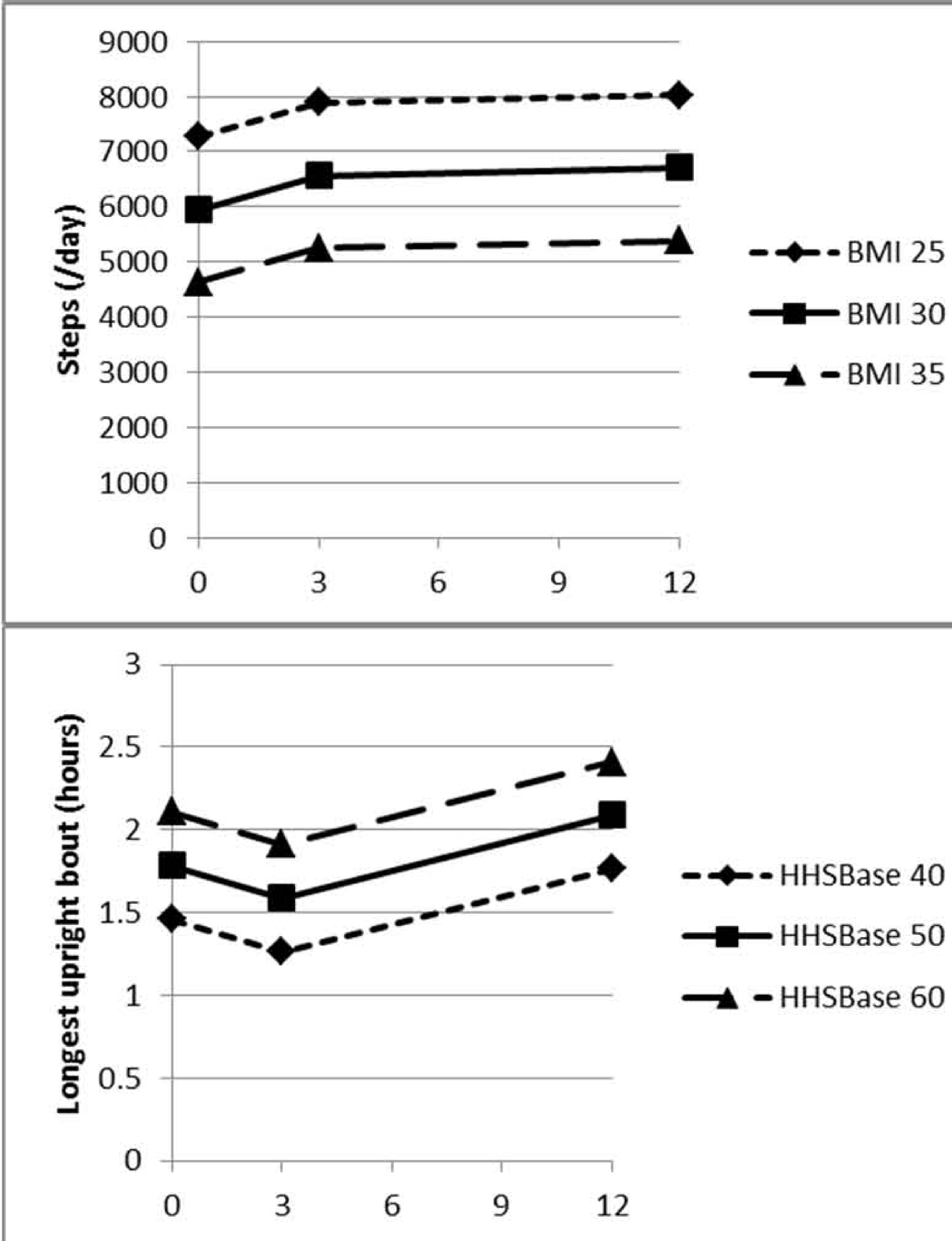

4000

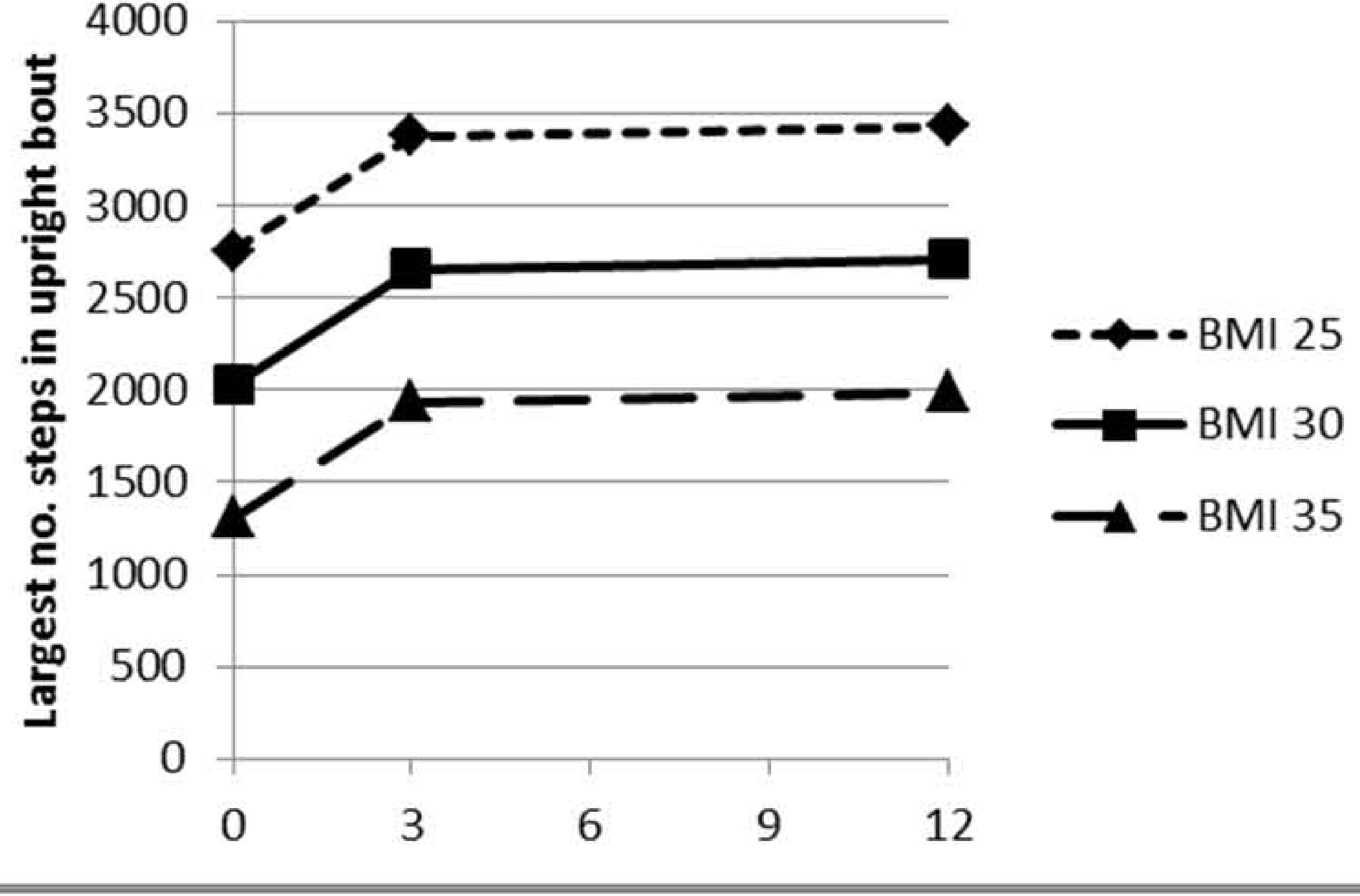

e)

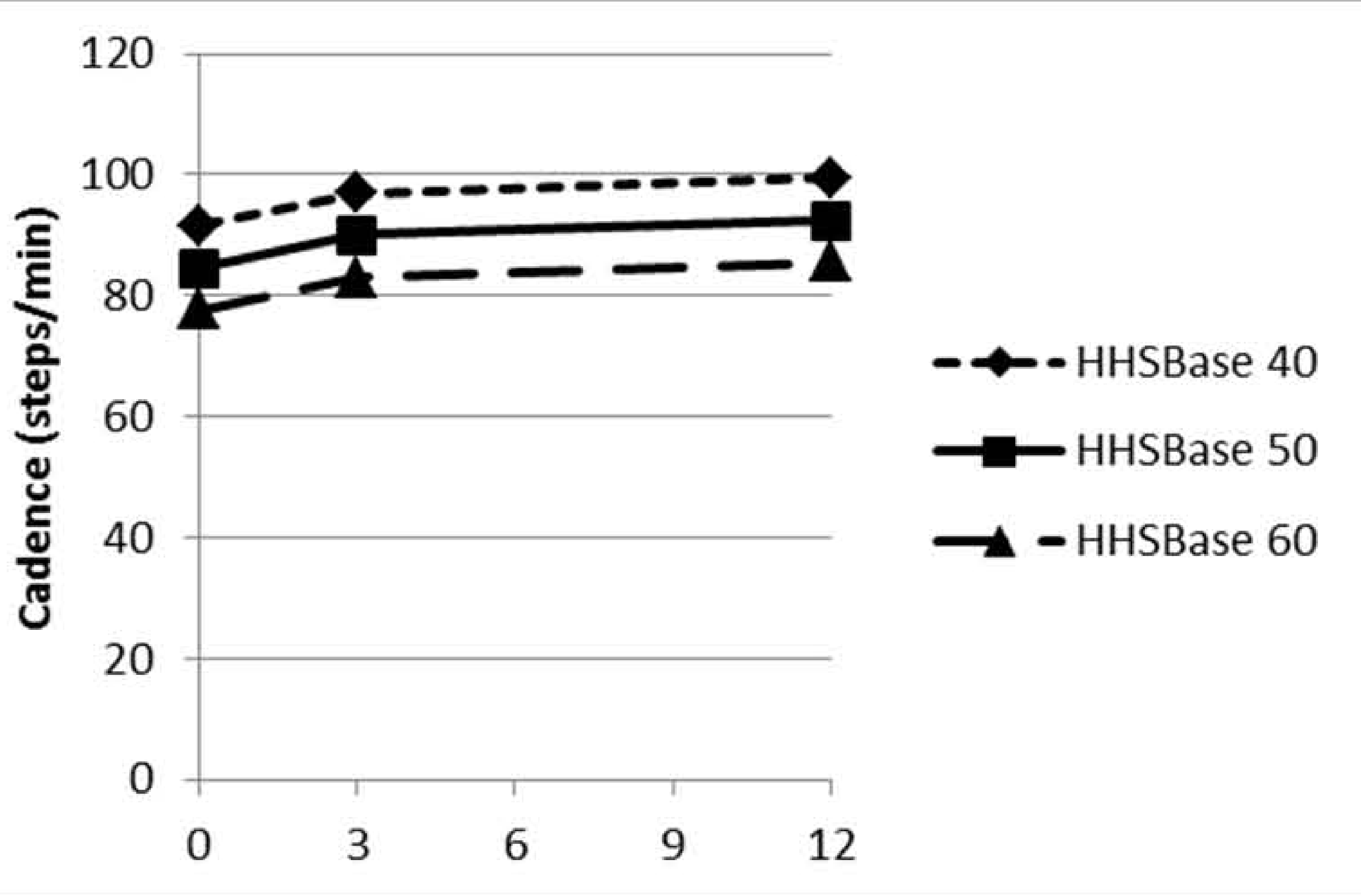

f)

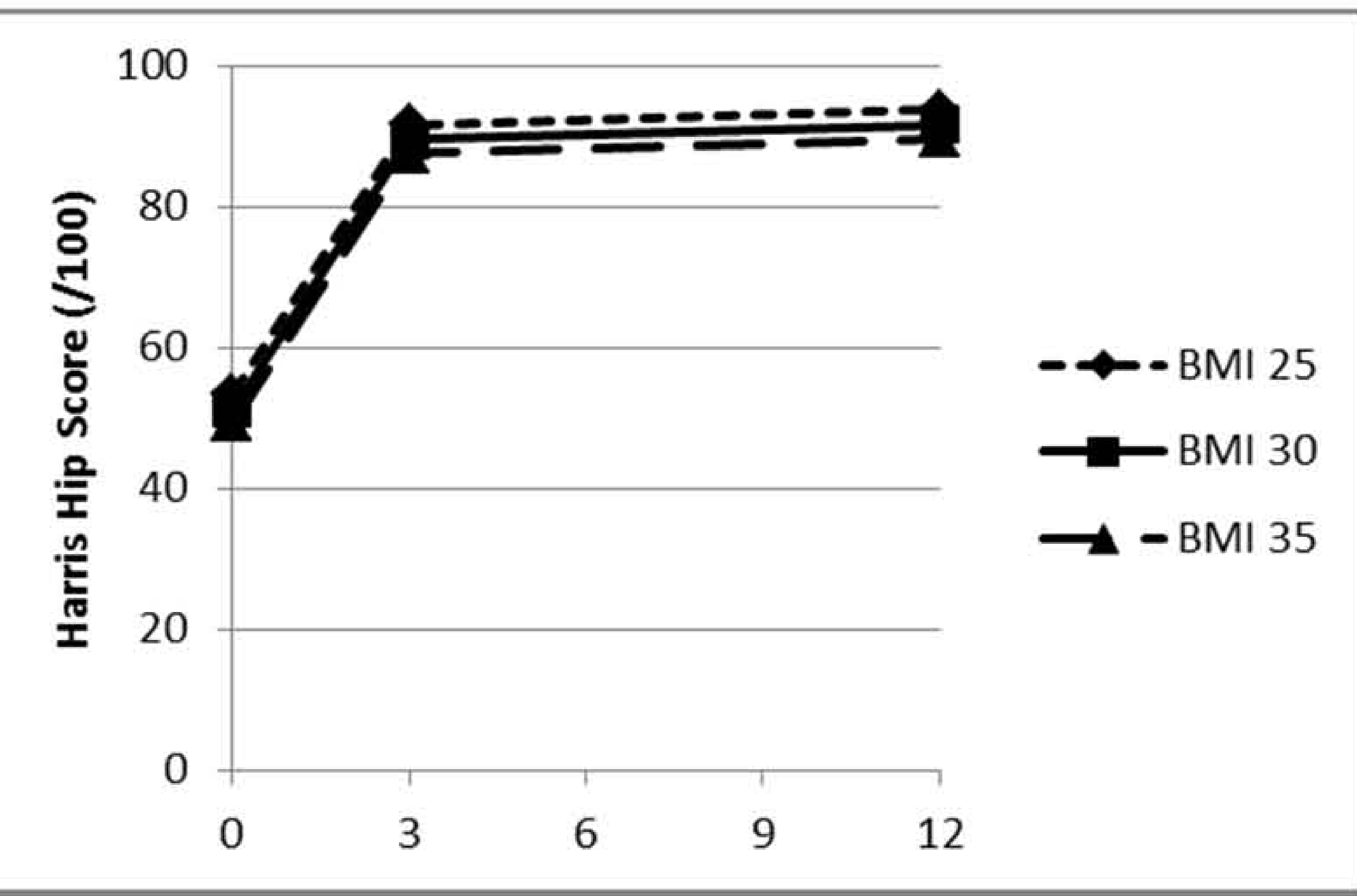

g)

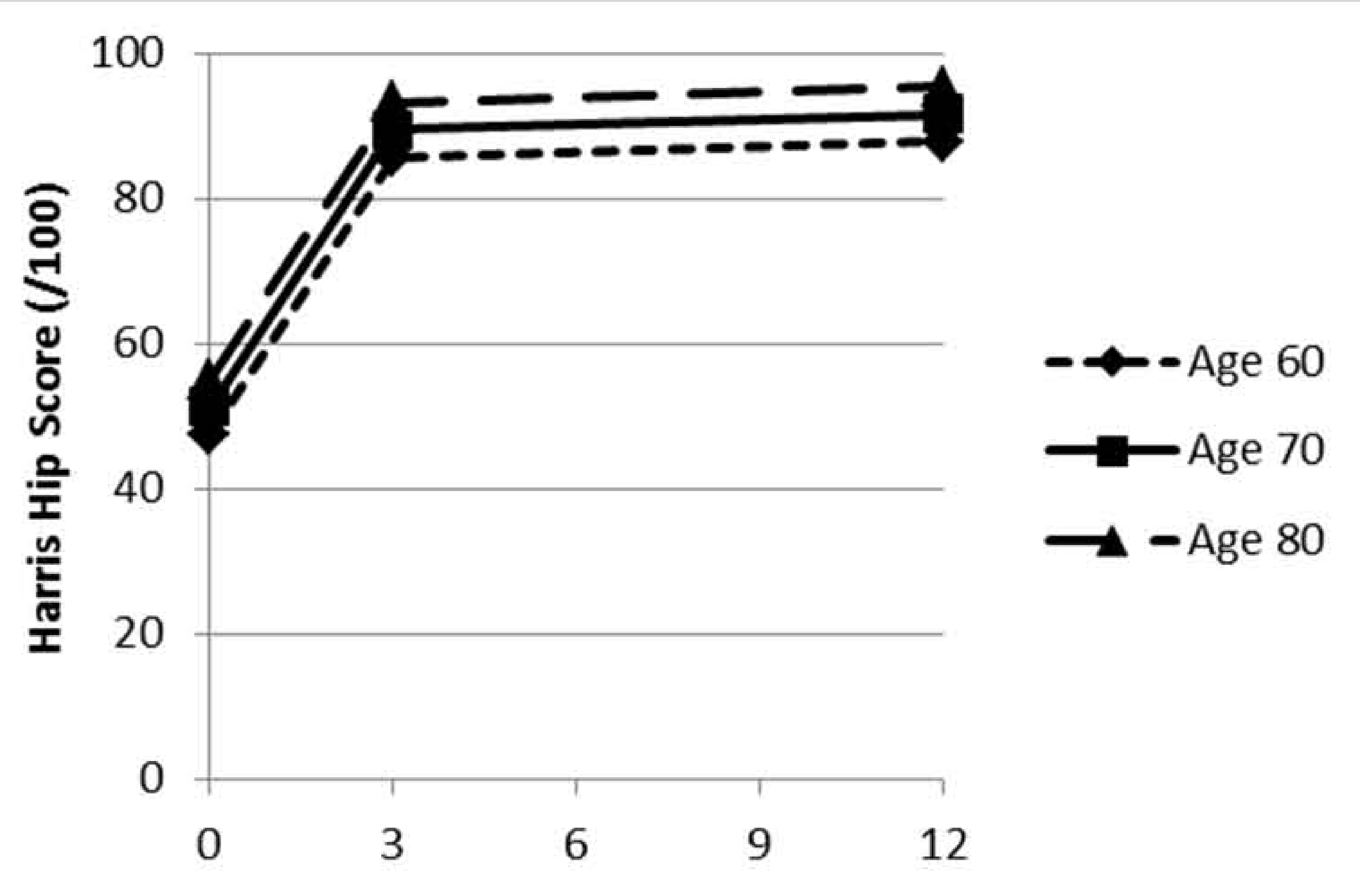

h)

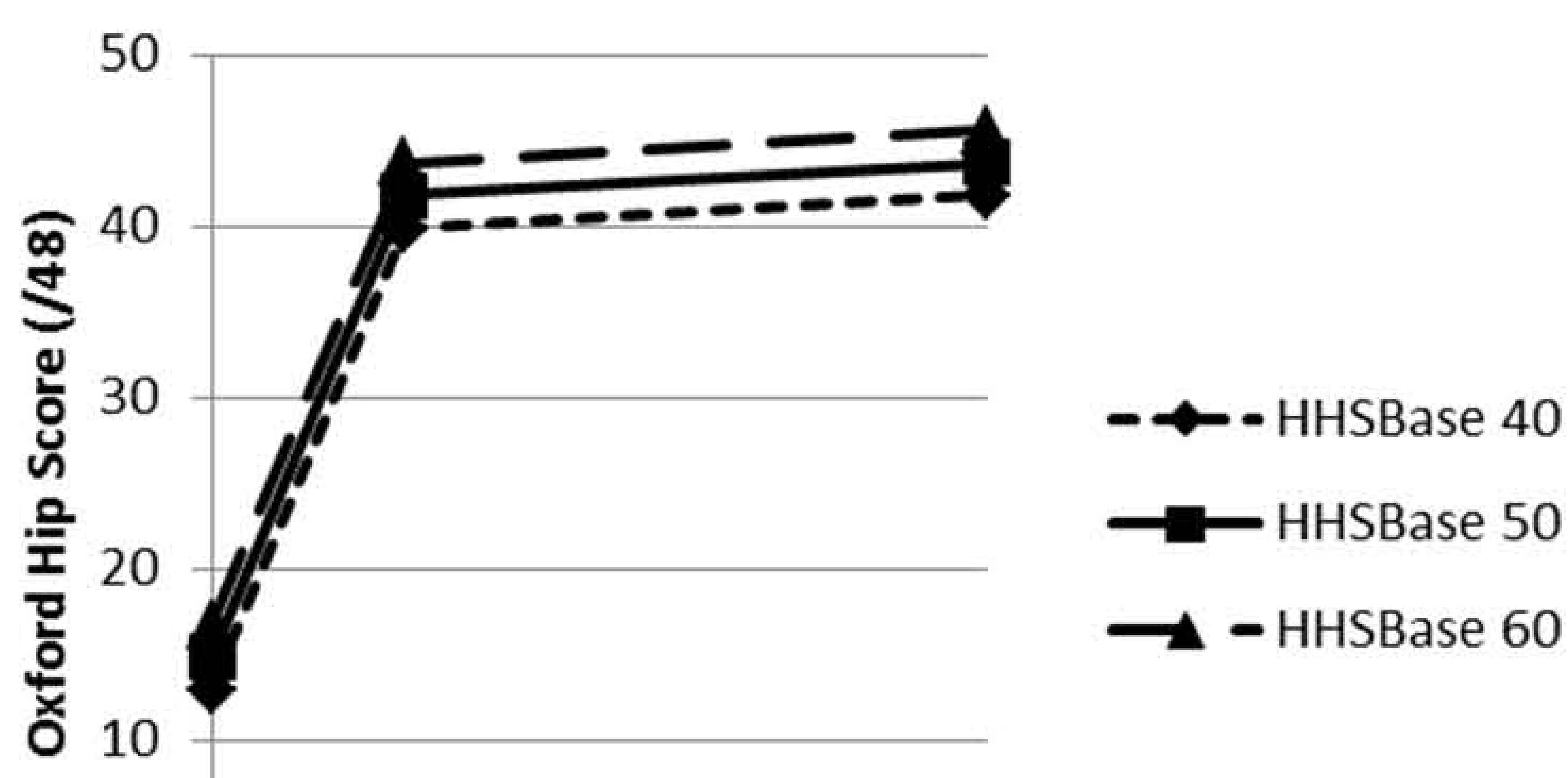

i)

0
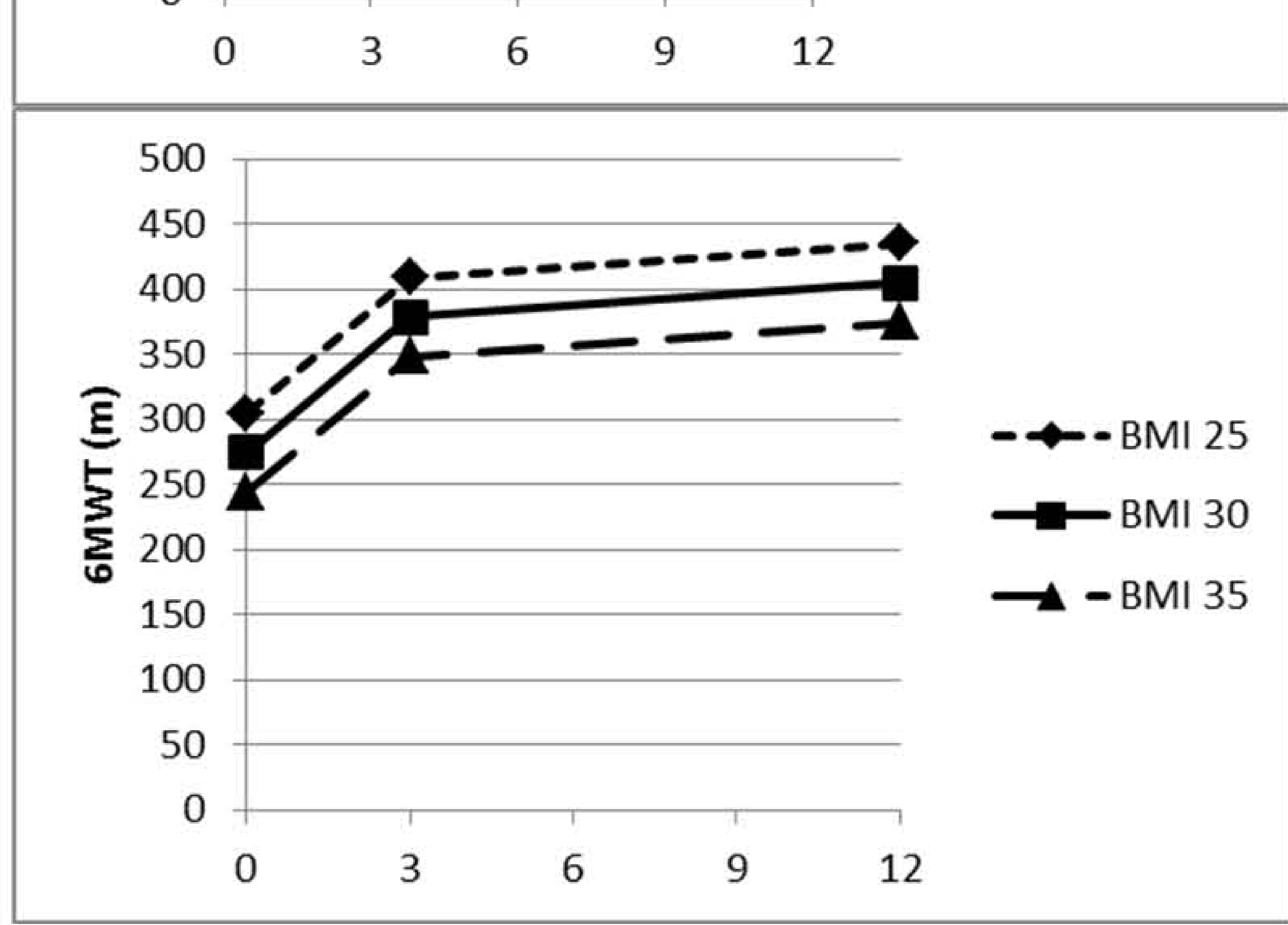
Table 1 Outcomes at each time point.

\begin{tabular}{|l|ccc|}
\hline Outcome & $\begin{array}{c}\text { Pre- } \\
\text { operative } \\
\text { (Mean SD) }\end{array}$ & $\begin{array}{c}\text { 3m Post- } \\
\text { operative } \\
\text { (Mean SD) }\end{array}$ & $\begin{array}{c}12 \text { m Post- } \\
\text { operative } \\
\text { (Mean SD) }\end{array}$ \\
\hline \multicolumn{1}{|c|}{ Primary outcomes } & & & \\
Sit-to-stand transitions (/day) & $46(11)$ & $44(11)$ & $44(11)$ \\
Upright time (hours/day) & $5.35(2.07)$ & $5.55(1.74)$ & $5.42(1.61)$ \\
Steps (/day) & $5320(3015)$ & $5943(2675)$ & $6155(2631)$ \\
Longest upright bout (hours) & & & $2.09(1.96)$ \\
Largest number of steps in an upright bout & $1934(1480)$ & $2559(1841)$ & $2671(1705)$ \\
Cadence of bouts >60s (steps/min) & $85(16)$ & $91(13)$ & $93(12)$ \\
Harris Hip Score (/100) & $50(10)$ & $88(10)$ & $91(11)$ \\
Oxford Hip Score (/48) & $15(6)$ & $42(7)$ & $44(6)$ \\
Six minute walk test (m) & $270(93)$ & $374(87)$ & $399(104)$ \\
\hline
\end{tabular}


Table 2 Mixed linear model results, both fixed and random parameters for all outcomes. Those elements of the model that are included produced an improvement in $2 \mathrm{LnL}$ of a minimum of 3.84. Variables were centred as: BMI $30 \mathrm{~kg} / \mathrm{m}^{2}$, Age 70 years, HHS Baseline 50 . Beta = change in outcome per unit of model element: Time (months), BMI $\left(\mathrm{kg} / \mathrm{m}^{2}\right.$ ), Age (years), HHS (Harris Hip Score) Baseline (score/100). 95\% confidence intervals are given.

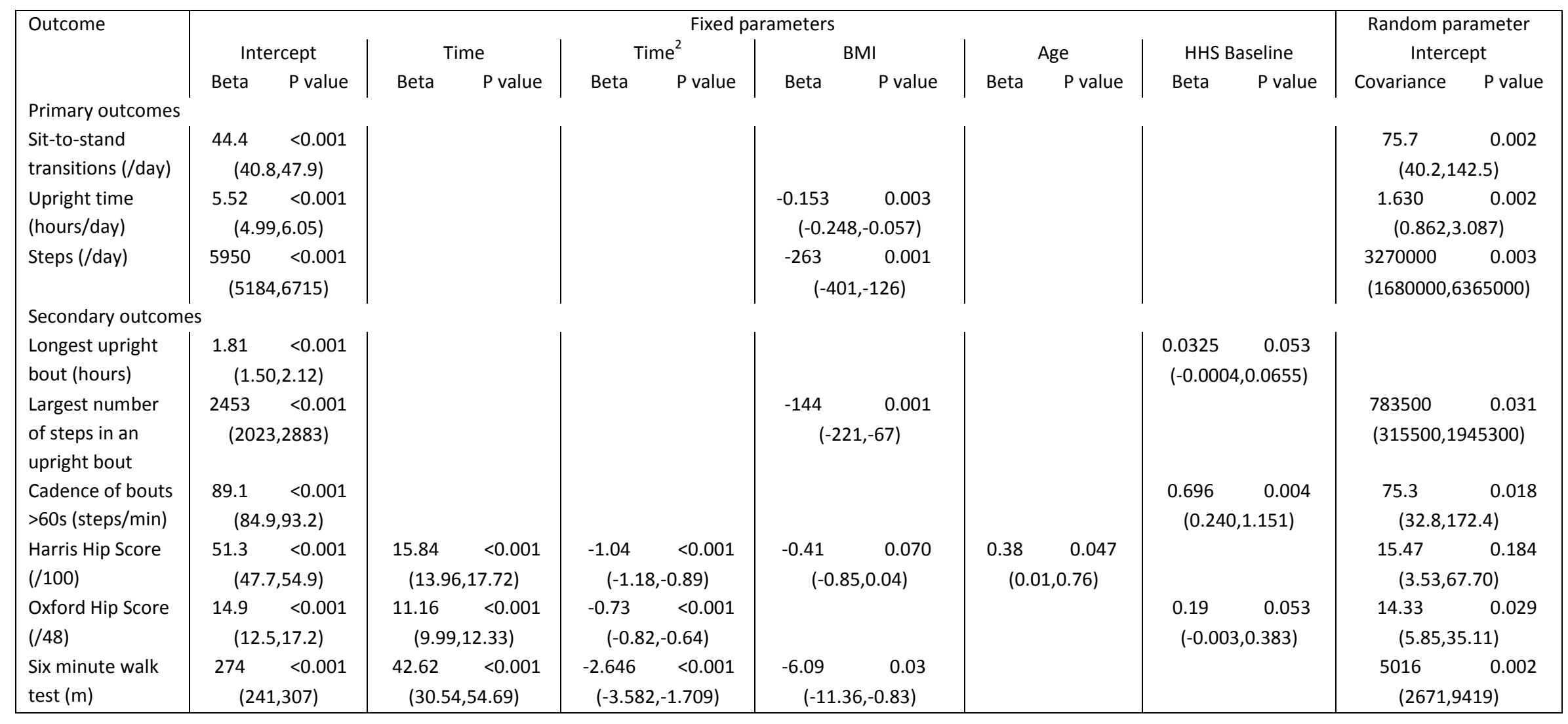




\section{Funding source}

This study was funded by Glasgow Caledonian University.

\section{Acknowledgements}

The authors would like to thank all participants in the study and the Rehab and Orthopaedic staff of the Golden Jubilee Hospital for their support in recruitment of participant. The authors thank Dr David McDonald (Golden Jubilee National Hospital) for his contribution to the development of the research study, through the provision of advice on project development and facilitating data collection. 